\title{
Unexpected discovery of prostatic diffuse large B-cell lymphoma after thulium laser vaporization in a patient with Waldenstrom macroglobulinemia
}

\author{
Jialei Wang ${ }^{1} \wedge$, Huilei Yan $^{1}$, Shuyan Tian², Lei Qin ${ }^{3}$, Yunbo Ma ${ }^{1}$ \\ ${ }^{1}$ Department of Urology, Liaocheng People's Hospital, Liaocheng, China; ${ }^{2}$ Department of Pathology, Liaocheng People's Hospital, Liaocheng, \\ China; ${ }^{3}$ Nuclear Medicine Center, Liaocheng People's Hospital, Liaocheng, China
}

Correspondence to: Yunbo Ma, MD. Department of Urology, Liaocheng People's Hospital, No.67 Dongchang West Road, Liaocheng 252000, China. Email: layweno@gmail.com.

Submitted Nov 30, 2020. Accepted for publication Jul 12, 2021.

doi: 10.21037/qims-20-1319

View this article at: https://dx.doi.org/10.21037/qims-20-1319

\section{Introduction}

Prostate lymphoma is not common in surgical prostatic specimens and accounts for less than $1 \%$ of the total. Rather, chronic lymphocytic leukemia and small lymphocytic lymphoma form the majority of all prostate lymphomas. Waldenstrom macroglobulinemia (WM) and diffuse large B-cell lymphoma (DLBCL) are subtypes of non-Hodgkin lymphoma (NHL). The former is indolent, while the latter is aggressive. DLBCL associated with WM is especially rare mainly on account of the histological transformation involved. We report a 75 -year-old man with WM who was initially diagnosed as benign prostate hyperplasia (BPH) despite abnormal prostatic uptake of ${ }^{18} \mathrm{~F}$-fluorodeoxyglucose (FDG) positron emission/computed tomography (PET/CT). In the end, prostate DLBCL was diagnosed due to emergence of a rapidly enlarged prostate after thulium vaporization (ThuVAP) for dysuria. Prior abnormal uptake of ${ }^{18} \mathrm{~F}$-FDG PET/CT by the prostate may be an indicator of prostate lymphoma. Moreover, surgical procedures may rapidly deteriorate the situation of prostate lymphoma. To our knowledge, this may be the first report of DLBCL associated with WM involving the prostate.

\section{Case presentation}

All procedures performed in studies involving human participants were in accordance with the ethical standards of the institutional and/or national research committee(s) and with the Helsinki Declaration (as revised in 2013). Written informed consent was obtained from the patient.

A 75-year-old man with a prior medical history of anemia reported a $10-\mathrm{kg}$ weight loss and complained of being white-faced and susceptible to fatigue over the previous year. He was admitted to the hematology department after checkup results indicated decreased white blood cell count and anemia. Enhanced CT scans of the chest and abdomen showed multiple pulmonary nodules in the left lung, an enlarged mediastinal lymph node, and a retroperitoneal lymph node $2.6 \mathrm{~cm}$ diameter. No positive results were found on gastroscopy. Immunoglobulin $\mathrm{M}$ (IgM) was $18.2 \mathrm{~g} / \mathrm{L}$ (reference range, 0.46-3.04 g/L). An MYD88 L265p gene mutation was detected and confirmed. Consequently, WM was confirmed with consideration to the above tests and the results of bone marrow aspiration and biopsy. The patient was further referred for ${ }^{18} \mathrm{~F}-\mathrm{FDG}$ PET/CT (Figure 1). Maximal intensity projection (MIP) imaging unexpectedly revealed abnormal prostatic FDG uptake, along with abnormal focal tracer accumulations in the left pulmonary nodule, and the mediastinal, retroperitoneal, and pelvic lymph nodes (Figure 1A). The transverse view of the prostate on CT (Figure 1E, arrow) did not reveal any obvious abnormal findings. However, PET (Figure 1B) and the PET/

\footnotetext{
$\wedge$ ORCID: 0000-0002-2119-3804.
} 

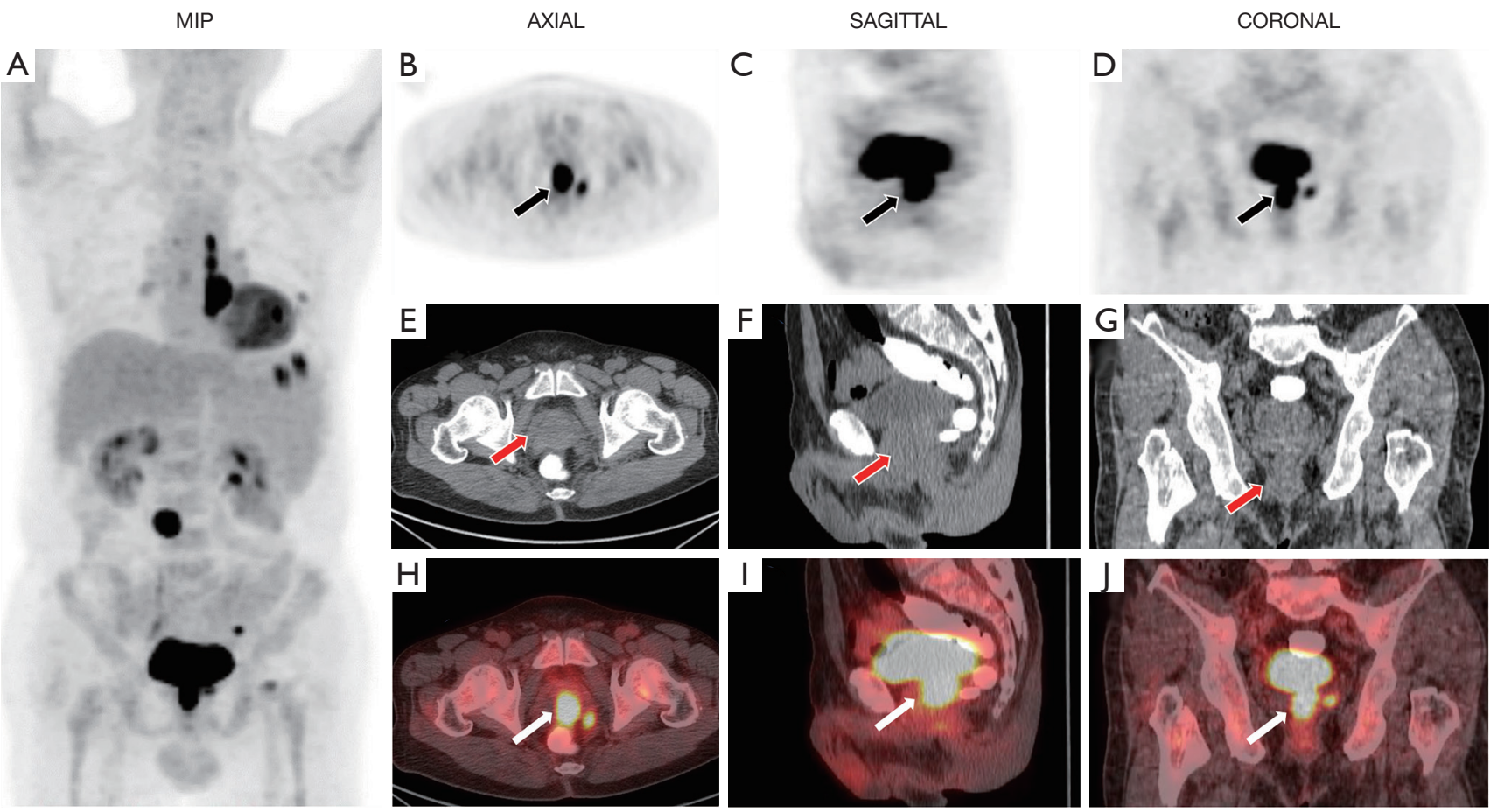

Figure 1 Images from ${ }^{18}$ F-FDG PET/CT for the WM patient. The images show abnormal tracer uptake of the prostate (SUVmax 27.0). Abnormal focal tracer accumulations in the left pulmonary nodule, and the mediastinal, retroperitoneal, and pelvic lymph nodes are also apparent. (A) MIP; (B-D) PET; (E-G) CT; (H-J) fused PET/CT. The prostatic lesion is indicated by the arrow. MIP, maximal intensity projection; PET, positron emission tomography; CT, computed tomography; WM, Waldenstrom macroglobulinemia; SUV, standardized uptake value.

CT fusion (Figure 1H) images displayed abnormal tracer uptake, with a standardized uptake value (SUV) max of 27.0. The sagittal (Figure 1C,1F,1I) and coronal (Figure 1D,1G,17) views were able to more clearly depict this phenomenon. The abnormal prostate tracer uptake was interpreted as the result of BPH and urinary retention. Finally, the patient chose the generic drug, ibrutinib (Beacon Pharmaceuticals Limited, Dhaka, Bangladesh) to treat the WM.

Six months later, the patient was admitted to the urology department for dysuria and nocturia. Several routine examinations were conducted: the prostate-specific antigen (PSA) level was normal, and findings from the parallel digital rectal examination (DRE) were consistent with BPH. The prostate diameter was $6.6 \mathrm{~cm} \times 6.0 \mathrm{~cm} \times 5.7 \mathrm{~cm}$, with a residual urine volume of $346 \mathrm{~mL}$ by ultrasound. The patient underwent routine ThuVAP successfully, with the dysuria symptoms being significantly relieved postoperatively. No specimen was left for histopathology check due to vaporization. One month later, the patient was readmitted for acute urinary retention and defecation disorders. Prostate magnetic resonance imaging (MRI) (Figure 2) was performed, which, surprisingly, revealed that the prostate volume had significantly increased to $107 \mathrm{~mm} \times 104 \mathrm{~mm} \times 179 \mathrm{~mm}$. The sagittal view (Figure 2B) of the prostate MRI clearly showed a large prostate mass (asterisk). The rectum in the image (Figure 2B) appeared obviously compressed by the enlarged prostate, which was causing defecation difficulty. Prostate carcinoma was highly suspected, despite the PSA level being normal. To resolve the inconsistency between the PSA level, MRI findings, and clinical judgment, transrectal ultrasound-guided prostate biopsy (TRUS-PB; 13-core) was performed. The specimen showed massive infiltration by pathologic B-cells expressing the CD20 antigen. Finally, the patient was diagnosed with histologically prostatic DLBCL. The prognosis of the patient was not good despite being administered one cycle of chemotherapy. Three months after ThuVAP, he was hospitalized again for massive hematemesis, which had 
AXIAL

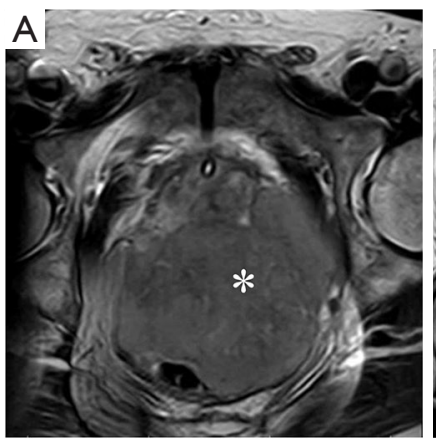

SAGITTAL

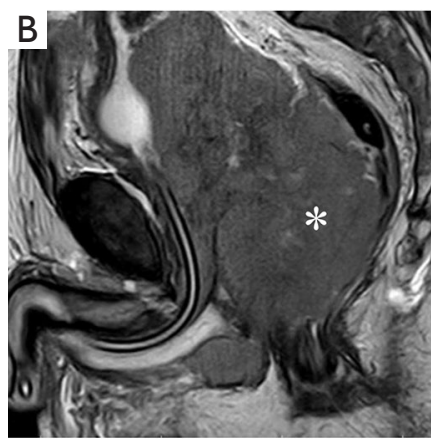

CORONAL

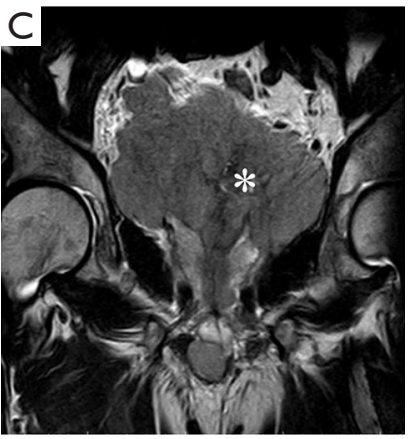

DWI

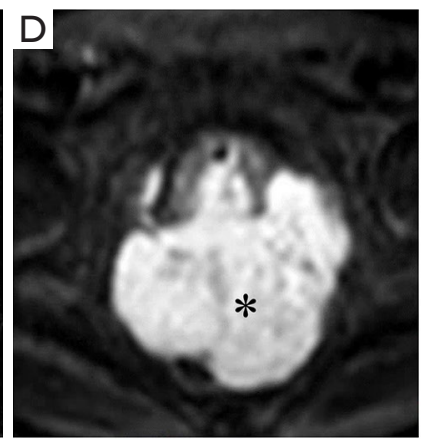

Figure 2 Prostate MRI images at 1 month after ThuVAP of the prostate. The images show locally enlarged prostate mass, measuring up to $107 \mathrm{~mm} \times 104 \mathrm{~mm} \times 179 \mathrm{~mm}$. The rectum was obviously compressed by the mass, which led to defecation difficulty in this case. The MRI report concluded that the mass was prostate carcinoma. The final biopsy histology was DLBCL of the prostate. (A-C) T2WI shows an equal signal; (D) DWI shows restricted diffusion with b value of $800 \mathrm{~s} / \mathrm{mm}^{2}$. (A) Axial view; (B) sagittal view; (C) coronal view; (D) DWI view. The prostatic lesion is marked by an asterisk. DWI, diffusion-weighted imaging; MRI, magnetic resonance imaging; ThuVAP, thulium vaporization; DLBCL, diffuse large B-cell lymphoma; T2WI, T2 weighted imaging.

completely incapacitated him. Gastroscopy showed multiple ulcers in the stomach indicative of lymphoma. No further treatment or chemotherapy was administered, as the patient abandoned medical treatment.

\section{Discussion}

WM is a neoplastic disease characterized by bone marrow infiltration with lymphoplasmacytic lymphoma and the presence of an IgM monoclonal component. Most patients show an indolent clinical course (1). The patient with WM usually presents with fatigue, weakness, anemia, weight loss, and night sweats (2). WM is characterized by MYD 88 mutation (2,3), with MYD88 L265P mutation occurring in $90 \%$ of WM cases (4). The manifestations in his case were highly consistent with the above symptoms and characteristics, and the patient undoubtedly had WM.

Prostate lymphomas are uncommonly encountered in surgical pathology practice. Fewer than $1 \%$ of prostate specimens demonstrate leukemia or lymphoma, and most are chronic lymphocytic leukemia/small lymphocytic lymphoma (5). Accordingly, DLBCL involving the prostate is rare and aggressive. In these cases, the patient mainly presents with rapid enlarging lymphadenopathy and constitutional symptoms, and there is a high frequency of extranodal disease (6).

However, it should be noted that DLBCL is known to occur in $2-10 \%$ of cases with antecedent WM (7).
Histological transformation is the main reason for this and usually leads to a poor outcome (1). Several reports have described this kind of transformation (8-10), which mainly involves the skin, central nervous system, kidney, bone, and pleura. To our knowledge, this seems to be the first report of a case with DLBCL of the prostate involving subsequent or metachronous WM.

Lymphoma involving the prostate is often an incidental finding following prostate biopsy or transurethral resection of the prostate (TURP) (11), and this is what occurred in our case. PET/CT can be used to determine the sites of disease with the SUV and possibly the site of most aggressive disease and to identify the preferred site of biopsy (6). We reviewed the patient's medical history, but PET/CT provided the most insight into the patient's condition at that time. Over the years, ${ }^{18} \mathrm{~F}$-FDG PET/CT has proven to be a valuable tool for detecting manifestations of lymphoma at diagnosis and is nowadays considered state of the art (12). The important role of PET/CT has been described in several studies in prostate lymphoma patients (5,13-15).

Histological transformation may be an indicator of adverse outcome, and we were able to glean the following lessons from our experience with this case: (I) timely TRUS$\mathrm{PB}$ is imperative when PET/CT shows prostatic abnormal tracer uptake even when the PSA level is normal. Incidental high FDG uptake in the prostate gland is rare. Generally, a low glucose metabolic rate in primary prostate carcinoma 
and physiological excretion of FDG through the urinary system may mask the FDG uptake in primary prostate carcinoma $(16,17)$. Prostate-specific membrane antigen (PSMA) PET/MR can be used in the evaluation of prostate carcinoma (18). Lower urinary tract symptoms (LUTS) are most commonly associated with $\mathrm{BPH}$, prostate cancer, and prostatic lymphoma (19). Further clinical manifestations of this case included a residual urine volume of $346 \mathrm{~mL}$ and a prostate diameter of $6.6 \mathrm{~cm} \times 6.0 \mathrm{~cm} \times 5.7 \mathrm{~cm}$ as detected by ultrasound before ThuVAP. Coincidentally, similar manifestations occur just before PET/CT is performed. In fact, $\mathrm{BPH}$ with urinary retention can sometimes mimic prostate lymphoma (19). (II) A comprehensive understanding of the past medical history is essential to understanding this case. (III) Multiple enlarged pelvic and retroperitoneal lymph nodes in PET/CT could provide sufficient warning for adequately managing this situation. Prostate lymphoma is a rare, nonnegligible malignant tumor that arises even when DRE and PSA are normal, with a few cases having elevated PSA level due to prostate lymphoma $(20,21)$.

TURP is safe in advanced prostate cancer patients and does not induce the local proliferation of tumor cells (22-25). This may give the impression that malignant prostate tumors cannot be influenced by surgical procedures; however, it seems that DLBCL of the prostate is the exception. In our case, a rapidly and locally enlarged prostate was found after ThuVAP. ThuVAP may lead to distant metastasis, such as the lymphoma-like-ulcer in the stomach in this case as evidenced in the second gastroscopy. Indeed, it appears that surgical operation can contribute to the deterioration of DLBCL of the prostate. To our knowledge, no similar cases have been reported in the literature thus far.

A certain obstinacy in the patient, demonstrated by the insistence on generic medication and refusal for further chemotherapy, might have been an obstacle to recovery in this case. The most common treatment for prostate DLBCL is chemoimmunotherapy (CI) with R-CHOP (rituximab, cyclophosphamide, doxorubicin, vincristine, and prednisone), which leads to cure in approximately $50-60 \%$ of patients (6). Ibrutinib is recommended for treatment for WM and is effective in both WM and DLBCL (7). Large randomized trials have indicated that subsequent consolidative irradiation of former bulky sites in advancedstage patients may have a positive effect on outcome (26). FDG-PET helps to guide the precise administration of chemotherapy and can help determine whether or not irradiation after chemotherapy is required. In aggressive NHL, baseline and interim PET imaging can also provide crucial information for disease prognosis (12).

\section{Conclusions}

${ }^{18}$ F-FDG PET/CT can offer a clear clue for establishing a correct diagnosis of prostate lymphoma and plays an important role in treatment and prognosis. Despite its rarity, DLBCL of the prostate should not be neglected. Surgical procedures such as ThuVAP may cause both the enlargement and discovery of the prostate DLBCL in patients with WM.

\section{Acknowledgments}

Funding: None.

\section{Footnote}

Conflicts of Interest: All authors have completed the ICMJE uniform disclosure form (available at https://dx.doi. org/10.21037/qims-20-1319). The authors have no conflicts of interest to declare.

Ethical Statement: The authors are accountable for all aspects of the work in ensuring that questions related to the accuracy or integrity of any part of the work are appropriately investigated and resolved. All procedures performed in studies involving human participants were in accordance with the ethical standards of the institutional and/or national research committee(s) and with the Declaration of Helsinki (as revised in 2013). Written informed consent was obtained from the patient.

Open Access Statement: This is an Open Access article distributed in accordance with the Creative Commons Attribution-NonCommercial-NoDerivs 4.0 International License (CC BY-NC-ND 4.0), which permits the noncommercial replication and distribution of the article with the strict proviso that no changes or edits are made and the original work is properly cited (including links to both the formal publication through the relevant DOI and the license). See: https://creativecommons.org/licenses/by-nc-nd/4.0/.

\section{References}

1. Jiménez C, Alonso-Álvarez S, Alcoceba M, Ordóñez GR, García-Álvarez M, Prieto-Conde MI, Chillón MC, Balanzategui A, Corral R, Marín LA, Gutiérrez NC, 
Puig N, Sarasquete ME, González M, García-Sanz R. From Waldenström's macroglobulinemia to aggressive diffuse large B-cell lymphoma: a whole-exome analysis of abnormalities leading to transformation. Blood Cancer J 2017;7:e591.

2. Shakeri A, Kaffenberger BH, Gru AA. Cutaneous macroglobulinosis as the initial presentation of Waldenström macroglobulinemia in a patient with a history of diffuse large B-cell lymphoma. J Cutan Pathol 2018;45:962-4.

3. Treon SP, Xu L, Yang G, Zhou Y, Liu X, Cao Y, Sheehy P, Manning RJ, Patterson CJ, Tripsas C, Arcaini L, Pinkus GS, Rodig SJ, Sohani AR, Harris NL, Laramie JM, Skifter DA, Lincoln SE, Hunter ZR. MYD88 L265P somatic mutation in Waldenström's macroglobulinemia. N Engl J Med 2012;367:826-33.

4. Yu X, Li W, Deng Q, Li L, Hsi ED, Young KH, Zhang M, Li Y. MYD88 L265P Mutation in Lymphoid Malignancies. Cancer Res 2018;78:2457-62.

5. Warrick JI, Owens SR, Tomlins SA. Diffuse large B-cell lymphoma of the prostate. Arch Pathol Lab Med 2014;138:1286-9.

6. Liu Y, Barta SK. Diffuse large B-cell lymphoma: 2019 update on diagnosis, risk stratification, and treatment. Am J Hematol 2019;94:604-16.

7. Talaulikar D, Biscoe A, Lim JH, Gibson J, Arthur C, Mackinlay N, Saxena K, Cheng YY, Chen VM. Genetic analysis of Diffuse Large B-cell Lymphoma occurring in cases with antecedent Waldenström Macroglobulinaemia reveals different patterns of clonal evolution. Br J Haematol 2019;185:767-70.

8. Hayashi Y, Sata H, Akuta K, Toda J, Kusakabe S, Ueda T, Ueda Y, Fujita J, Tadokoro S, Maeda T, Nishimura J, Shibayama H, Oritani K, Kanakura Y. Diffuse large B-cell lymphoma occurring in a Waldenström macroglobulinemia patient with central nervous system infiltration. Rinsho Ketsueki 2015;56:2351-6.

9. Shingaki S, Yoshiki Y, Yamamoto K, Ota Y, Suzuki K. Coexistent adrenal diffuse large B cell lymphoma in a patient with Waldenström's macrogloblinemia/ lymphoplasmacytic lymphoma. Ann Hematol 2016;95:1723-4.

10. Durot E, Tomowiak C, Michallet AS, Dupuis J, Hivert B, Leprêtre S, et al. Transformed Waldenström macroglobulinaemia: clinical presentation and outcome. A multi-institutional retrospective study of 77 cases from the French Innovative Leukemia Organization (FILO). Br J Haematol 2017;179:439-48.
11. Hodgson R, Huang Y'T, Steinke K, Ravi Kumar AS. FDGPET/CT in evaluation and prognostication of primary prostate lymphoma. Clin Nucl Med 2010;35:418-20.

12. Voltin CA, Mettler J, Grosse J, Dietlein M, Baues C, Schmitz C, Borchmann P, Kobe C, Hellwig D. FDGPET Imaging for Hodgkin and Diffuse Large B-Cell Lymphoma-An Updated Overview. Cancers (Basel) 2020;12:601.

13. Meijer D, Wondergem M, Knol RJJ, Broos WAM, van der Zant FM. 18F-DCFPyL Uptake in an Incidentally Detected Follicular Lymphoma by PET/CT Performed for Biochemically Recurrent Prostate Cancer. Clin Nucl Med 2020;45:e96-7.

14. Wang K, Wang N, Sun J, Fan Y, Chen L. Primary prostate lymphoma: A case report and literature review. Int J Immunopathol Pharmacol 2019;33:2058738419863217.

15. Pan B, Han JK, Wang SC, Xu A. Positron emission tomography/computerized tomography in the evaluation of primary non-Hodgkin's lymphoma of prostate. World J Gastroenterol 2013;19:6699-702.

16. Jadvar H. Is There Use for FDG-PET in Prostate Cancer? Semin Nucl Med 2016;46:502-6.

17. Lee ST, Lawrentschuk N, Scott AM. PET in prostate and bladder tumors. Semin Nucl Med 2012;42:231-46.

18. Domachevsky L, Goldberg N, Gorenberg M, Bernstine H, Groshar D, Catalano OA. Prostate cancer evaluation using PET quantification in 68Ga-PSMA-11 PET/MR with attenuation correction of bones as a fifth compartment. Quant Imaging Med Surg 2020;10:40-7.

19. Chu PG, Huang Q, Weiss LM. Incidental and concurrent malignant lymphomas discovered at the time of prostatectomy and prostate biopsy: a study of 29 cases. Am J Surg Pathol 2005;29:693-9.

20. Oosterheert JJ, Budel LM, Vos P, Wittebol S. High levels of serum prostate-specific antigen due to PSA producing follicular non-Hodgkin's lymphoma. Eur J Haematol 2007;79:155-8.

21. Tomaru U, Ishikura H, Kon S, Kanda M, Harada H, Yoshiki T. Primary lymphoma of the prostate with features of low grade B-cell lymphoma of mucosa associated lymphoid tissue: a rare cause of urinary obstruction. J Urol 1999;162:496-7.

22. Dellabella M, Branchi A, Gasparri L, Claudini R, Castellani D. Oncological safety and quality of life in men undergoing simultaneous transurethral resection of bladder tumor and prostate: results from a randomized controlled trial. World J Urol 2018;36:1629-34.

23. Pansadoro V, Sternberg CN, DePaula F, Florio A, 
Giannarelli D, Arcangeli G. Transurethral resection of the prostate and metastatic prostate cancer. Cancer 1991;68:1895-8.

24. Qu M, Zhu F, Chen H, Lian B, Jia Z, Shi Z, Li J, Wang Y, Sun Y, Gao X. Palliative Transurethral Resection of the Prostate in Patients with Metastatic Prostate Cancer: A Prospective Study of 188 Patients. J Endourol 2019;33:570-5.

25. Lee DH, Chung DY, Lee KS, Kim IK, Rha KH, Choi YD, Chung BH, Hong SJ, Kim JH. Clinical experiences

Cite this article as: Wang J, Yan H, Tian S, Qin L, Ma Y. Unexpected discovery of prostatic diffuse large B-cell lymphoma after thulium laser vaporization in a patient with Waldenstrom macroglobulinemia. Quant Imaging Med Surg 2022;12(1):862-867. doi: 10.21037/qims-20-1319 of incidental prostate cancer after transurethral resection of prostate (TURP) according to initial treatment: a study of a Korean high volume center. Yonsei Med J 2014;55:78-83.

26. Held G, Murawski N, Ziepert M, Fleckenstein J, Pöschel V, Zwick C, Bittenbring J, Hänel M, Wilhelm S, Schubert J, Schmitz N, Löffler M, Rübe C, Pfreundschuh M. Role of radiotherapy to bulky disease in elderly patients with aggressive B-cell lymphoma. J Clin Oncol 2014;32:1112-8. 